\title{
Risk assessment of plastic pollution on marine diversity in the Mediterranean Sea
}

\author{
Montserrat Compa a,*, Carme Alomar ${ }^{\mathrm{a}}$, Chris Wilcox ${ }^{\mathrm{b}}$, Erik van Sebille ${ }^{\mathrm{c}, \mathrm{d}}$, Laurent Lebreton ${ }^{\mathrm{e}}$, \\ Britta Denise Hardesty ${ }^{\mathrm{b}}$, Salud Deudero ${ }^{\mathrm{a}}$ \\ a Instituto Español de Oceanografia, Centro Oceanográfico de Baleares, Palma 07015, Spain \\ ${ }^{\mathrm{b}}$ Commonwealth Scientific and Industrial Research Organization, Oceans and Atmosphere Business Unit, Hobart, Tasmania. 7000, Australia \\ c Grantham Institute, Imperial College London, London SW7 2AZ, United Kingdom \\ d Institute for Marine and Atmospheric Research, Utrecht University, Utrecht, Netherlands \\ e The Ocean Cleanup Foundation, Rotterdam 2014, Netherlands
}

\section{H I G H L I G H T S}

- Mediterranean marine diversity is at high risk of plastic exposure.

- A signal regression improves modelling exposure to plastic debris.

- Species' homerange and life history traits predicted plastic ingestion.

- Coastal areas are hotspots for plastic ingestion.
GR A P H I C A L A B S T R A C T

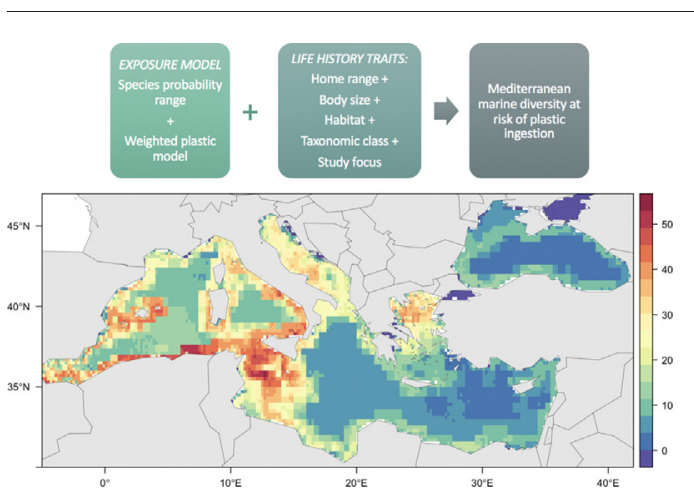

\begin{abstract}
A B S T R A C T
Plastic marine pollution is an increasing threat to global marine diversity. Quantifying this threat is particularly difficult and complex, especially when evaluating multiple species with different ecological requirements. Here, we examine the semi-enclosed basin of the Mediterranean Sea where the inputs of plastic pollution and its impact on marine diversity are still widely unknown. Eighty-four species from six taxonomic classes were evaluated to assess the risk of ingesting plastic marine debris, integrating inter-specific factors such as plastic exposure rates and life history traits (e.g., motility, habitat, and body size). Species were modelled within a spatial context to identify and estimate their exposure to plastic ingestion across the Mediterranean Sea using literature data, species distribution maps and plastic dispersion models. Our approach identified hotspots for the risk of plastic ingestion across multiple taxa in the Mediterranean Sea, highlighting that coastal species are at higher risk of ingesting plastic in the marine environment than open-sea species. The plastic exposure analysis indicated that species with larger home ranges were more at risk of exposure with increased distances while local species were more likely to be exposed to plastic closer to the centre of their home range location. The approach used in this study can be applied to support management and mitigation efforts throughout the Mediterranean Sea and in other geographic regions to minimize the impact of plastic pollution on marine diversity.
\end{abstract}

(c) 2019 Elsevier B.V. All rights reserved.

\footnotetext{
* Corresponding author.

E-mail address: montse.compa@ieo.es (M. Compa).
} 


\section{Introduction}

Plastic pollution is a major threat to marine and terrestrial ecosystems globally (Derraik, 2002). Worldwide, it is estimated that between 4 and 12 million tonnes of plastic enters the world's oceans annually, primarily from coastal inputs (Boucher and Friot, 2017; Jambeck et al., 2015; Neufeld et al., 2016). Marine plastic has become a growing global concern with regional and local governments, communities and stakeholders instituting measures to minimize its impacts on marine and coastal communities. In recent years, these concerns have led to an increase in studies highlighting the need for unifying research and action to better understand, evaluate and manage the mechanisms by which plastic waste enters the marine environment (Jambeck et al., 2015; Jeftic et al., 2009).

The high volume of plastic pollution reported in the oceans has raised concerns about the potential for widespread impact on marine flora and fauna. Over the past several decades, laboratory and field research into the effects of plastic exposure on marine species across the globe has increased (Gall and Thompson, 2015). Plastic pollution has been shown to result in ingestion of plastic materials by marine species, entanglement which can cause direct and indirect harm or death in addition to colonization leading to the movement of alien species (Alomar and Deudero, 2017; Rodríguez et al., 2013; Taylor et al., 2016). Globally, plastic ingestion has been reported in the gastrointestinal tracts of marine species, from deep sea invertebrates to large mammals, and across different habitats, including demersal and pelagic habitats (de Stephanis et al., 2013; Lusher et al., 2013; Taylor et al., 2016). Some of the principal sources of marine litter are coastal zones, river emissions and lost or discarded fishing gear (Löhr et al., 2017). The impact of plastic pollution is far-reaching in marine ecosystems and identifying areas of high risk is an essential step, especially as a management tool towards reducing these impacts. Global predictions on the impact of plastic pollution to different species of seabirds and sea turtles indicate that the risk extends well beyond the affected locations to the high seas (Schuyler et al., 2016; Wilcox et al., 2015).

Although marine plastic is a global issue, the Mediterranean Sea has been identified as one of the most polluted areas. Recent models have estimated between $3.2 \times 10^{12}-28.2 \times 10^{12}$ small plastic particles floating on the sea surface from data collected using neuston nets during sea surface trawls (van Sebille et al., 2015). Overall, between 873 and $2576 \mathrm{t}$ of plastic debris is estimated to be floating on the sea surface (Suaria et al., 2016). This is concerning because the Mediterranean Sea is a hotspot for marine diversity and harbours an estimated $4 \%$ to $18 \%$ of the world's marine species (Bianchi and Morri, 2000). There is a high level of endemism, with over 600 of the marine species in the basin being vertebrates (Bianchi and Morri, 2000). Human activities are the principal threat to biodiversity loss in the Mediterranean Sea because they lead to overexploitation of marine resources, habitat loss and pollution. Spatial patterns of biodiversity through time demonstrate an overall decrease in species richness throughout the basin (Coll et al., 2010). Plastic pollution has been identified as a threat to marine diversity through location and species-specific surveys; however, there is still a lot of uncertainty about the location of hotspot areas and how much of the marine community is threatened (Deudero and Alomar, 2015). Although these risks have been quantified at the global scale for several species, such as in sea turtles and seabirds (Schuyler et al., 2016; Wilcox et al., 2015), it is necessary to quantify the risk at the regional scales across multiple species, incorporating factors such as home range and life history traits of the region. To factor in the variation in motilities across multiple species, it is important to consider home range as it gives an indication of the likelihood of where a species might be found any given time to consider the variation in motilities across multiple species. In addition, it is essential to include marine species occupying similar ecological niches at a finer spatial resolution for a better evaluation of the overall impact of plastic pollution on the marine community.
Risk assessment of the Mediterranean basin for plastic pollution will provide the data necessary for highlighting the species under threat and identifying hotspot risk areas (Dawson et al., 2011; Fossi et al., 2017). In this study, we combined numerical sea surface plastic estimations and species distribution maps with observed plastic ingestion from published and unpublished literature to evaluate which species are most under threat and to identify the location of hotspot risk areas are for a multitude of species (Dawson et al., 2011; Fossi et al., 2017). By including species with different ecological histories, it was necessary to incorporate each species' home range to account for differences in where and how species move. In addition to the home range, life history traits were integrated to determine exposure and predict the risk of ingestion of plastic to marine fauna in the Mediterranean Sea. The risk assessment was developed to a) model the exposure of species using local and regional home ranges, b) predict ingestion risk across species and c) evaluate the threat posed by plastic pollution to marine diversity in the region.

\section{Methods}

\subsection{Plastic ingestion literature review}

We compiled research articles on marine plastic ingestion through a search in three major scientific databases: Scopus, ISI Web of Knowledge, and Google Scholar. We used key research terms reported in Deudero and Alomar, 2015 to search for documents published from 1986 to 2017. The search returned 26 documents comprising scientific articles, $\mathrm{PhD}$ theses and grey literature, from which we extracted data on the ingestion of plastic litter in the Mediterranean Sea (see Supplementary material S5 and S6). We collected information on the ecological and life history traits of each species identified in our literature review and incorporated into the models the following parameters identified from the review: geographic location, motility (home range), body size, habitat, taxa classes and study focus.

For each species-study observation, the geographic coordinates were considered individually. This resulted in a data point for each species and the study location. However, not all study-species observations were geo-referenced and their locations were estimated based on the study location provided in the literature as a proxy. Given the variability of home ranges, motility was defined as a proxy for the home range for each species by assigning each distribution range as local (capable of local movement) or regional (regional/basin-scale movement). For instance, the small pelagic fish bogue (Boops boops) was considered to have local motility, while the swordfish (Xiphias gladius) was considered to have regional motility (see Supplementary material S1a and $\mathrm{S} 1 \mathrm{c})$. For body size, the mean total length $(\mathrm{mm})$ was recorded whenever available from the literature. If the total length was not reported in the study, the common length reported from either Fishbase (www. fishbase.org) or FAO (www.fao.org) was included. Species were categorized as either of two habitats, pelagic or demersal, to cover the range of predominant habitat. Feeding is an ecological habitat function associated with the use of feeding grounds or at least the presence of adults; thus, the feeding habitat most associated with adults for each species was assigned (Seitz et al., 2013). Due to the wide range of species involved in this study and the limitations with respect to replication within taxa, we modelled the ecological differences among study species at the class level. Finally, to give an indication of objectivity from the studies included in the literature review, a study focus categorized by the binary yes/no was assigned to each study depending on whether the principal objectives of the study were to determine plastic ingestion or whether plastic was identified during a general diet analysis while examining the gut contents.

\subsection{Species distribution}

Species native distribution maps from AquaMaps (http://www. aquamaps.org/, accessed on November 16th, 2016), were used to assess 
the relative probability of occurrence of each of the selected marine species at different locations in the Mediterranean Sea (Kaschner et al., 2013). The native range maps of species distributions were generated using occurrence data on the distribution and habitat usage of a species which included parameters such as depth range, temperature, salinity and geographic range limit. If more than one model prediction was available for the native range map, the latest computer-generated model including the newest available data was selected. For this study, two distribution range maps were used. The first type of species distribution was a binary range where populations are considered homogeneous across their range with a cell value of one if present and a cell value of zero if absent (see Supplementary material S1a and S1c). The binary range model was estimated by using the probability species range from the occurrence map as a mask and assigning the value of one wherever occurrence probability was greater than zero (binary range). The second species distribution considered was the probability occurrence range, selected to give an indication of species heterogeneity across the range. For these ranges, each cell value indicates the probability of species occurrence across their range (probability range) (see Supplementary material S1b and S1d).

\subsection{Numerical plastic model}

Recent numerical modelling of plastic litter distribution has given an insight into the global magnitude of floating plastics in the world's oceans (van Sebille et al., 2015). A comparison was made between three independent models for plastic circulation in the Mediterranean Sea: the Lebreton (Lebreton et al., 2012), Maximenko (Maximenko et al., 2012) and van Sebille (van Sebille et al., 2015) models. The most parsimonious numerical model was the Lebreton 2012 model. The surface modelling of the Lebreton model is a probability prediction of plastic litter on a $0.2^{\circ} \times 0.2^{\circ}$ grid using realistic input scenarios of anthropogenic material and ocean circulation to simulate 30 years of litter transport and accumulation within the Mediterranean Sea (Lebreton et al., 2012) (see Supplementary material S2). For these reasons, this plastic accumulation model was used to calculate the exposure of plastic litter to Mediterranean marine diversity.

\subsection{Modelling plastic exposure}

Two principal approaches were used to estimate the exposure of species to plastic pollution. First, to estimate an encounter rate with plastic pollution across each species' native range, we applied similar methodologies used in previous risk assessments for seabirds and marine turtles (Schuyler et al., 2016; Wilcox et al., 2015). The first approach used species distribution range, either binary (presence/absence) or probability (species abundance), as a measure of species abundance. The binary exposure model estimated the exposure of marine plastic within the distribution range of each species by multiplying the numerical plastic model by the binary range. The probability exposure model, on the other hand, multiplies the numerical plastic model with the species' probability range for each of the species, while considering the probability of species presence. These are the non-weighted exposure models and consider exposure across the entire distribution range of a species without considering plastic distance within a species' home range location. The second approach was to use a distance weighting over each range of the species' distribution to estimate density exposure, considering whether species were more likely to encounter marine plastic closer to their core home range based on their sampling location. For each weighted scenario (binary distribution and probability distribution), the median and mean density of plastic litter was estimated using a great-circle distance matrix in log base 2 scale for each species-study location within a $250 \mathrm{~km}$ radius distance constraint (see Supplementary material S3). This $250 \mathrm{~km}$ radius weighting was used as a proxy for inverse distance weighting, allowing plastic pollution near the species-study observation to have more weight than plastic pollution further away. For each scenario, two metrics, mean and median, were calculated for each approach and the combination of weighted and non-weighted models (Wilcox et al., 2015). The summary of the eight possible exposure models is presented in Table 1, including the sample weighting, exposure model and metric.

To determine which of the weighted and non-weighted exposure models were best-fit to explain plastic exposure, a generalized additive model (GAM) with a binomial distribution was used to estimate each range scenario; the occurrence of ingestion for each species-study observation was the response variable. Models were tested for goodness of fit and the most parsimonious model was chosen using the Akaiki's Information Criteria (AIC), which is commonly used to determine the best-fit model (Burnham and Anderson, 2003).

\subsection{Estimating ingestion probability}

A key uncertainty in estimating the ingestion risk for species is identifying the feeding area. This area determines a species' exposure to plastic. Since this is generally unreported (only the study location or sampling location is usually reported), we estimated the relevant area of exposure using a signal regression approach. A signal regression allows the estimation of a function within the context of a linear model term, as opposed to a single coefficient, thus allowing for dependence on the predictor functions (Leathwick et al., 2006). In this application, we calculated the median density of plastic in bands of increasing radius, radiating outward from study location. We then estimated a function that provides a weighting for each band when calculating the relationship between plastic density and ingestion probability. This function estimates the relative importance of plastic exposure at increasing distances from the study locations, based on the observed percent ingestion from the studies we collected. Finally, an interaction term was included between motility class and the signal regression term to allow organisms with different levels of motility to have differing distance weighting functions for plastic pollution. A generalized additive model (GAM) with a binomial distribution (using a signal regression approach with linear functional terms for motility) was applied to predict the risk of plastic exposure. The result is the following full model:

$g\left(m u_{i}\right) \sim s_{1}\left(\operatorname{sum}_{j} L_{i j} f\left(x_{i j}\right)\right)+s_{2}\left(\operatorname{sum}_{j} L_{i j} f\left(z_{i j}\right)\right)+s_{3}($ body size $)$ + habitat + class + study focus

where dependent $g\left(m u_{i}\right)$ is the response variable the rate of occurrence of ingested plastics for each species-study combination. The $g\left(m u_{i}\right)$ depends on the linear function of the matrix densities of plastic litter for regional species $\left(x_{i j}\right)$ and local species $\left(z_{i j}\right)$, and the fixed weight distance matrices from the best litter exposure model $\left(L_{i j}\right)$ of the sum of the smooths across distances (serving as a proxy for species' motility range). We compared sub-models within the full model given above using the lowest AICc (Akaike Information Criterion corrected) to find the most parsimonious model. Sub-models included body size ( $\mathrm{mm})$, habitat, study focus and the taxa class. The best-fit from the binomial logistic regression model was then used to determine which covariates

Table 1

Results from the generalized additive model (GAM) exposure models of ingestion rates of plastic pollution using weighted and non-weighted means and medians across the Mediterranean Sea.

\begin{tabular}{llll}
\hline Weighting & Exposure model & Metric & AIC \\
\hline Yes & Probability & Median & 1348.4 \\
Yes & Probability & Mean & 1376.1 \\
Yes & Binary & Median & 1445.3 \\
Yes & Binary & Mean & 1462.4 \\
No & Probability & Median & 1678.9 \\
No & Probability & Mean & 1679.7 \\
No & Binary & Median & 1672.7 \\
No & Binary & Mean & 1679.7 \\
\hline
\end{tabular}


were significant in predicting litter ingestion. A starting model that included all predictor variables was then simplified using a backward stepwise procedure to remove terms making a non-significant contribution (R Core Team, 2017). All statistical modelling was performed in the $\mathrm{R}$ statistical language using the mgcv package (Leathwick et al., 2006; Wood, 2007).

\subsection{Mediterranean hotspots}

The results from the best-fit model were predicted at each centralized cell location across the home range of each species to determine hotspot areas where species are most at risk of ingesting marine plastic from exposure, resulting in predicted risk exposures to plastic pollution at species levels. The prediction cell values were then summed up for each species to determine the risk of species ingesting plastic based on their taxonomical level. Finally, a global risk model was calculated by summing up the cell values for each of the 84 considered species from the results of the predicted ingestion risk to determine a global risk of plastic litter ingestion across the Mediterranean Sea.

\section{Results}

A total of 143 species-study combinations were identified from 84 species from the 26 studies in the literature review (Fig. 1A). Regional motility was reported in thirty-two species-study combinations and local motility (the movement within the home range) was reported for 111 species. Studies on seafloor species (demersal) were predominant at $62.9 \%$, followed by $37.1 \%$ for pelagic species. The most speciesstudy observations were the Class Actinopterygii, which were reported in $74.8 \%$ of the studies, while the least species-study observations were the for the Class Cephalopoda, reported in only $2.1 \%$ of the studies
(Fig. 1B). Body size (by class) ranged from $0.10 \pm 0.70 \mathrm{~m}$ (Malacostraca) to $9.05 \pm 7.44 \mathrm{~m}$ (Mammalia) (Fig. 1C). Finally, nearly two thirds (65\%) of the published studies were specifically looking for plastic ingestion. The literature review for plastic ingestion identified several studies where plastic was found during diet studies or necropsies, although it was not the primary objective of the original study. To consider the potential bias from plastic identified in the literature, study focus was included as a factor.

\subsection{Modelling plastic exposure}

A total of eight exposure models were calculated to determine which model best explained the exposure of each species to the plastic debris fields. The weighted median density of plastic debris within a $250 \mathrm{~km}$ buffer, considering the motility of each species, was found to be the best-fit predictor for modelling plastic exposure, identified by the lowest Akaike Information Criterion (AICc $=1348.4$ ). This explains $14 \%$ of the deviance in the regression model (Table 1). Results from the partial effects for the smooths for each of the exposure scenarios are shown in Fig. 2. The plastic exposure analysis indicated that species with larger home ranges were more at risk of exposure with increased distances (GAM, $p<0.001$ ) while local species were more likely to be exposed to plastic closer to the centre of their home range location (GAM, $p<$ 0.001 ) (Fig. 2C and D). These results provided the baseline for predicting the ingestion risk when the plastic exposure across each of the species' distribution range is incorporated.

\subsection{Predicting ingestion risk}

All life history traits were incorporated into the most parsimonious plastic exposure model. The best-fit model incorporated the baseline
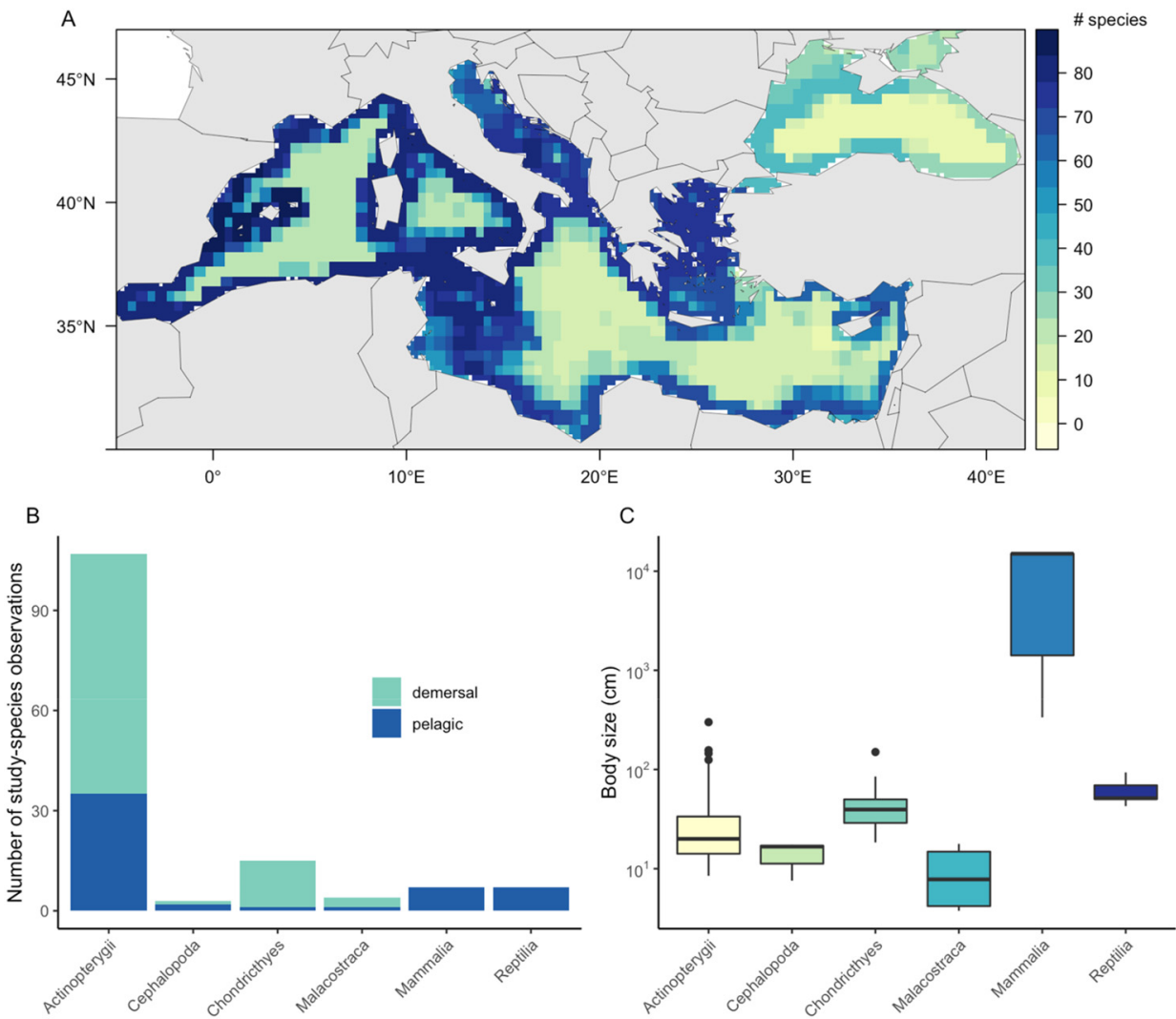

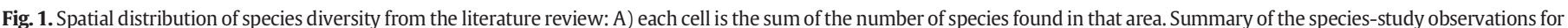

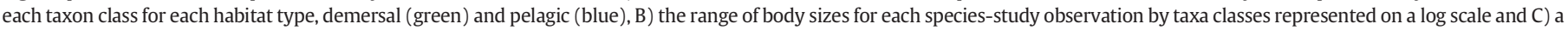
total of 143 species-study observations from 84 species were considered. 

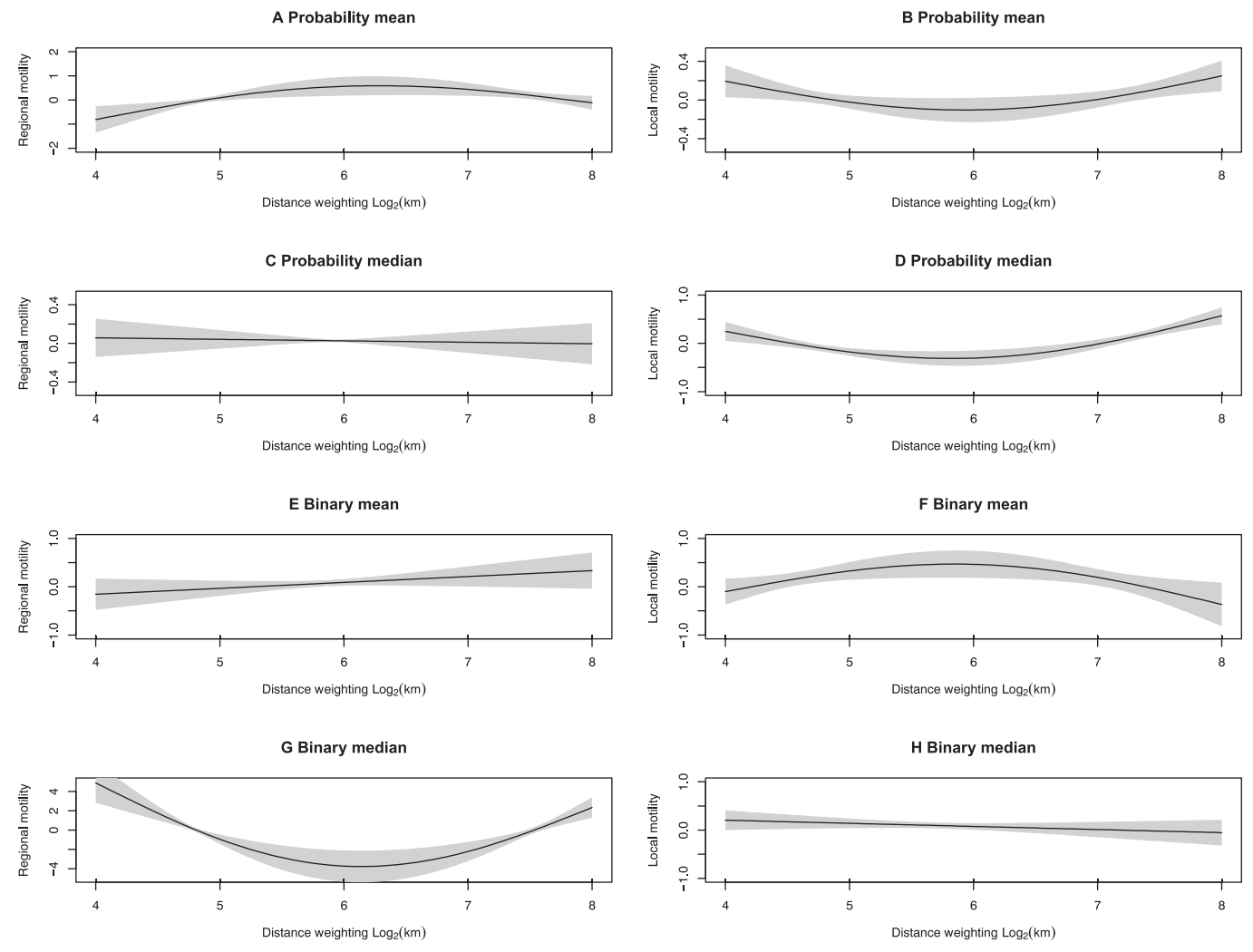

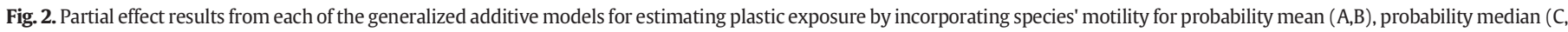
D), binary mean $(E, F)$ and binary median $(\mathrm{G}, \mathrm{H})$. Regional motility corresponds to offshore home ranges and local motility for species with coastal home ranges.

exposure model, along with the terms for motility, body size, habitat, taxa classes and study (GAM, AICc $=934.8$ ). This model explained $51 \%$ of the deviance in the ingestion data obtained from the literature (Table 2). Species observed to have local motility ranges were significantly more at risk of ingesting plastic where plastic loads were locally high $(n=111, p<0.001)$. Similar results were found for species with regional motility ranges, where the more motile species were at a higher risk of ingesting plastic found further away from their location within their home range $(n=32, p<0.05)$ (Table 3$)$. In addition, the pelagic habitat was significantly different from the demersal species (GAM, $p$ $<0.05$ ) and all classes of species differed significantly from one another except for species from the class Cephalopoda (Table 3).

The most parsimonious exposure model incorporated all life history traits and was used to predict the risk of ingestion across the distribution ranges for each of the 84 species in the Mediterranean Sea on a $0.2^{\circ} \times 0.2^{\circ}$ spatial grid. Predictions of the risk of ingesting plastic pollution across the region at each grid cell ranged from 0.7 to 53.1 for the species with a median value of 10.1 species and a mean of 14.7 species (Fig. 3A). Although these areas did not overlap with the areas of high

\section{Table 2}

Model parameters from the best-fit GAM binomial model for the following: Base (includes regional and local motility), habitat, body size, class, and study focus. Models were ranked by AICc.

\begin{tabular}{ll}
\hline Model & AICc \\
\hline Base + habitat + body size + taxonomic class + study focus & 934.8 \\
Base + body size + taxonomic class + study focus & 936.4 \\
Base + habitat + body size + taxonomic class & 1000.7 \\
Base + taxonomic class & 1101.8 \\
Base + habitat + body size & 1279.8 \\
Base + habitat + body size + study focus & 1282.1 \\
Base + body size & 1289.1 \\
Base + habitat & 1334.8 \\
Base + study focus & 1347.9 \\
Null & 1677.8 \\
\hline
\end{tabular}

concentrations of plastic pollution, they did coincide with areas of high species diversity, especially in the coastal regions. High-risk areas were located in both the eastern and western Mediterranean Sea, especially along the Spanish Mediterranean Coast and northern African coastline (Fig. 3B and C).

The probability predictions for each class, which ranged from 0 to 1.0 (rescaled), indicated that most fish species from the class Actinopterygii had a minimum probability of 0.001 and a maximum probability of 0.40 of ingesting plastic pollution. For some species such as those in the Class Chondrichthyes, the expected probability of species ingesting plastic varied from 0.007 to 0.69 . Classes such as Mammalia, also had similar ranges from 0.08 to 0.67 but with a higher median probability of 0.28 (Fig. 4A and E). It is important to note that although the overall number of mammal and reptile species within the Mediterranean Sea is low (Otero and Conigliaro, 2012), results indicate a high probability of

Table 3

Results from the best-fit generalized additive model incorporating the effects for the life history traits (habitat, taxonomic class and study focus) and the smooth terms for motility and body size.

\begin{tabular}{llllll}
\hline Model parameters & Estimate & (Std. Error) & z value & $\operatorname{Pr}(>|\mathrm{z}|)$ & \\
\hline (Intercept) & -90.76 & -17.6 & 5.13 & $2.51 \mathrm{E}-07$ & $* * *$ \\
Pelagic Habitat & -0.28 & -0.13 & 2.11 & 0.035 & $*$ \\
Cephalopoda class & -0.01 & -1.26 & 0.003 & 0.9974 & $* * *$ \\
Chondricthyes class & 1.66 & -0.2 & -8.25 & $<2 \mathrm{e}-16$ & $* *$ \\
Malacostraca class & -1.27 & -0.6 & 2.1 & 0.0355 & $*$ \\
Mammalia class & 1492.06 & -298.66 & -5 & $5.86 \mathrm{E}-07$ & $* * *$ \\
Reptilia class & 3.99 & -0.21 & -18.21 & $<2 \mathrm{e}-16$ & $* * *$ \\
Study focus yes & -0.88 & -0.1 & 8.13 & $4.16 \mathrm{E}-16$ & $* * *$ \\
Smooth coefficients & edf & Chi.sq & p.value & & \\
Regional & 2 & 9.03 & 0.011 & $*$ & \\
Local & 2.84 & 144.4 & $<2 \mathrm{e}-16$ & $* * *$ & \\
Body size $(\mathrm{cm})$ & 8.96 & 153.42 & $<2 \mathrm{e}-16$ & $* * *$ & \\
\hline
\end{tabular}

${ }^{*} p<0.05$.

${ }^{* *} p<0.01$.

${ }^{* * *} p<0.001$. 


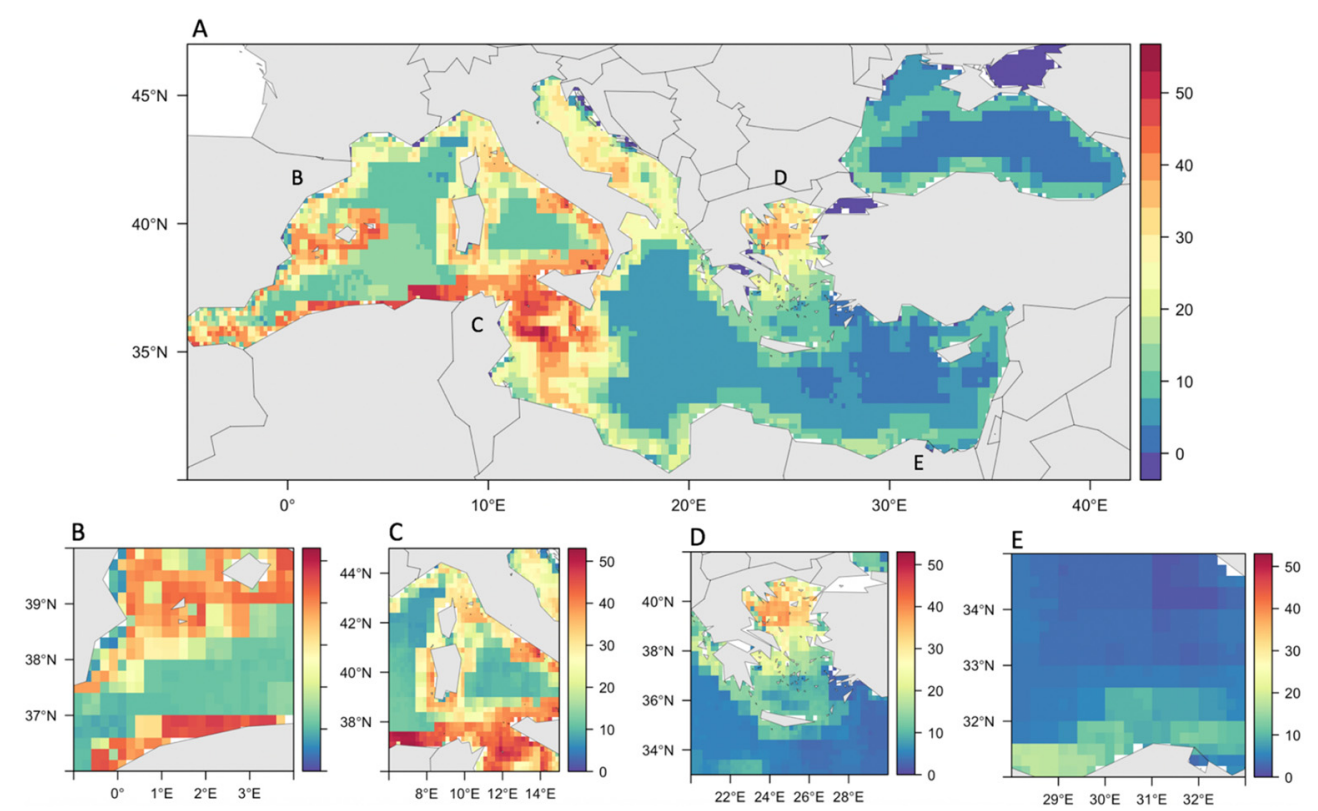

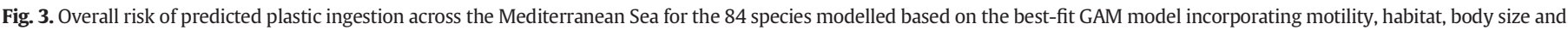

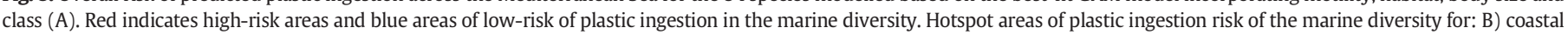

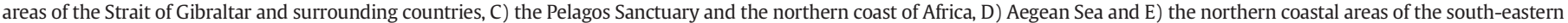
Mediterranean Sea.

ingesting plastic marine debris throughout their range. For example, the probability of ingesting marine plastic for the sea turtle species Carretta carretta ranged between 0.34 and 0.46 and is quite uniform across its range (Fig. 4C).

Observations in pelagic habitats significantly differed from demersal habitats (GAM, $p<0.05$ ), with demersal specie more likely to ingest marine plastic. The number of study-species at risk of plastic ingestion in pelagic habitats ranged from 0.6 to 4.9 species with a probability of ingestion between 0.001 and 0.50 . A higher number of species (0.06-14.2) were at risk in demersal habitats with a probability of ingestion similar to pelagic species (from 0.001 to 0.49 ) (Fig. 5B). Not only were differences found between habitats and size significant, but also classes were significantly different from the reference class Actinopterygii (ordered alphabetically), except for the class Cephalopoda (Table 3). Our analysis identified a significant relationship with body size (GAM, $p<0.001$ ), indicating that those species with larger body sizes were at higher risk of ingesting higher amounts of plastic pollution (Table 3). Finally, significant differences were found between the studies with a focus was on plastic debris and studies whose focus was not on the identification of plastic ingestion (GAM, $p$ $<0.001$ ). Studies that were focused on debris ingestion reported its occurrence more frequently than studies that were not focused on plastic
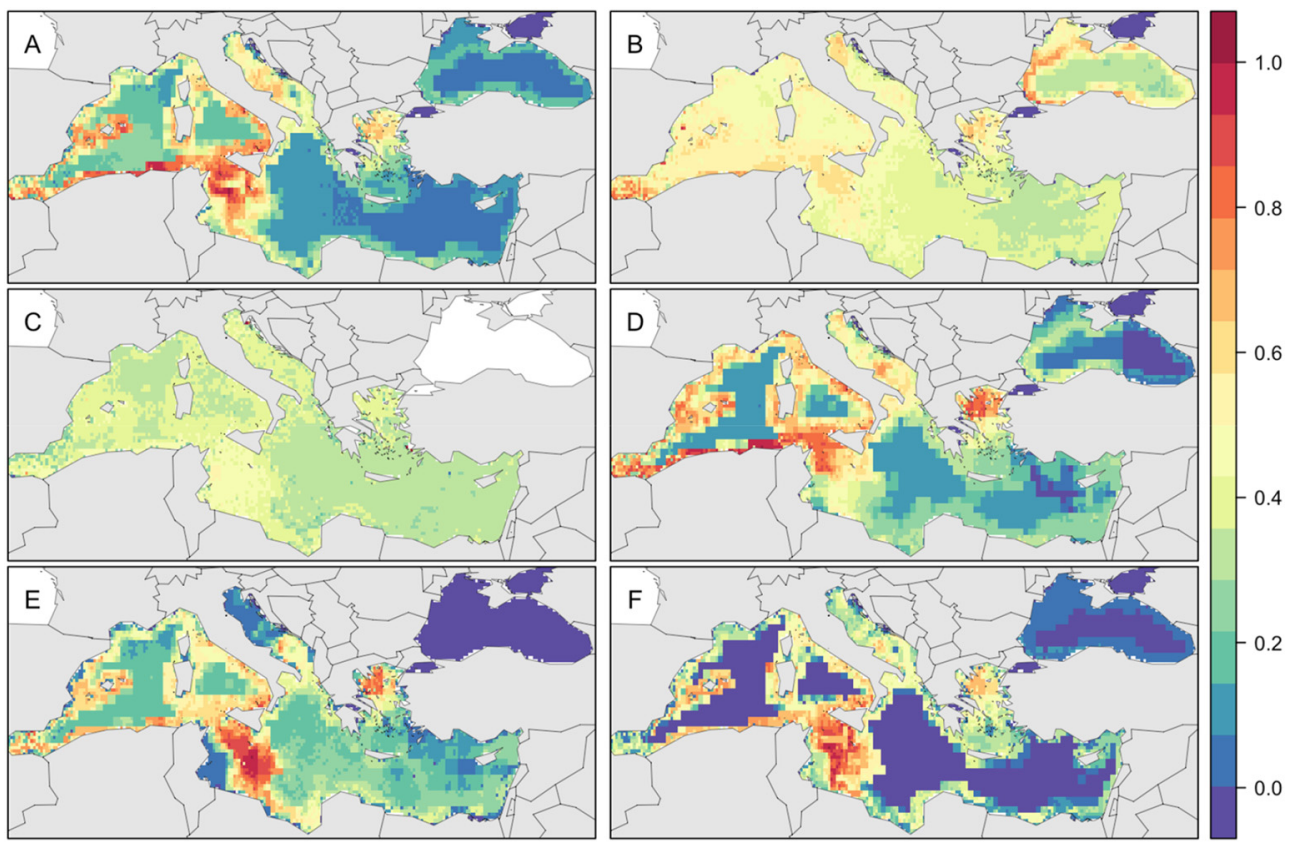

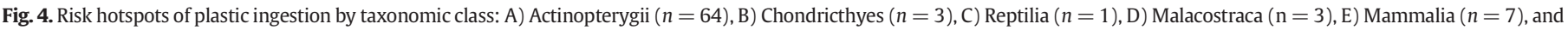

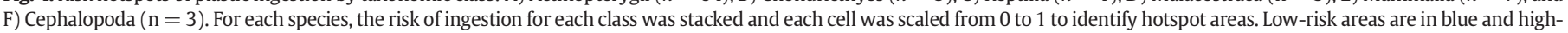
risk areas are in red. 

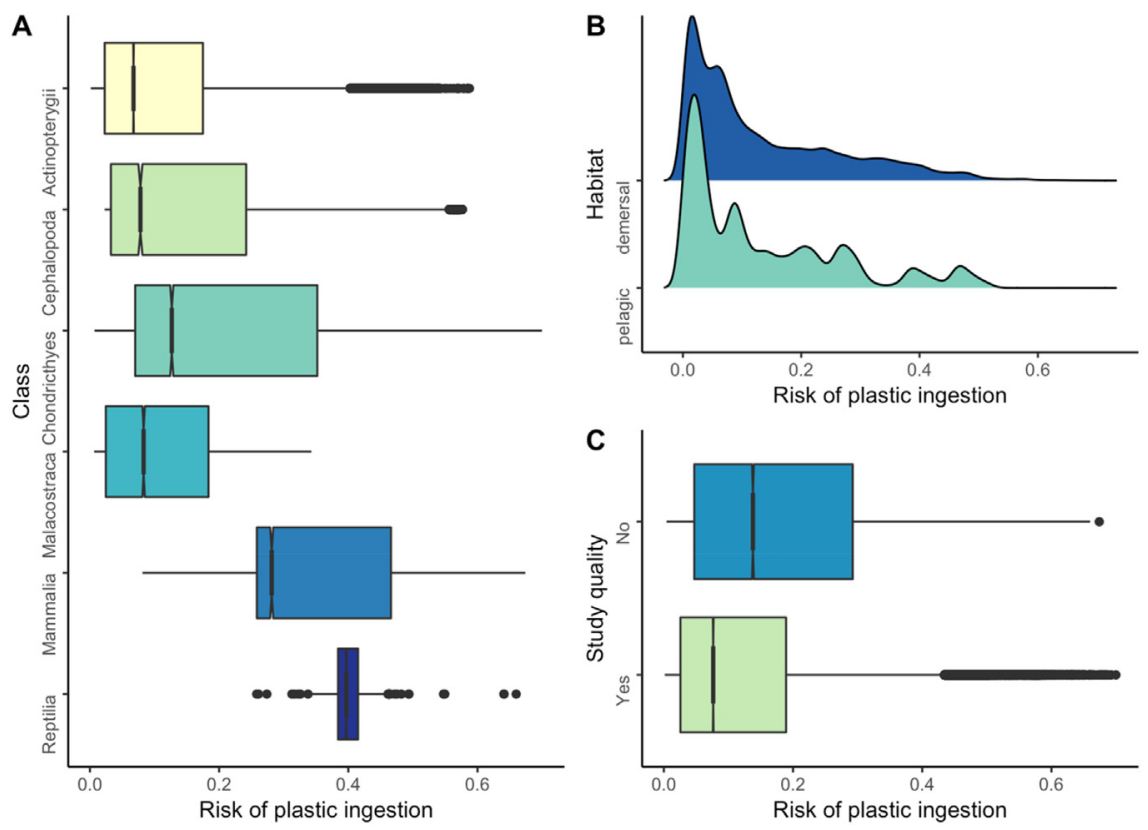

Fig. 5. The risk of ingestion (0-1) of plastic marine debris for the terms: A) species class, B) habitat (pelagic and demersal) and C) study focus.

debris ingestion (Fig. 5C). Overall, coastal marine species rather than offshore species were at the highest risk of encountering plastic pollution, while species with regional home ranges were found to be at reduced risk of plastic ingestion.

\section{Discussion}

Applying a risk framework to evaluate exposure to plastic pollution using a multi-species approach incorporating home range, ecology and life history traits is a challenging yet significant improvement to risk assessment modelling of plastic ingestion in the marine environment. Species and their locations cannot be considered in isolation; instead studies should approach multiple species occupying the same areas at the same time. Previous studies have investigated single taxonomic groups at a large scale, but this is the first study to evaluate a large suite of species with different life forms, motilities, body sizes and other traits within an entire sea basin (Schuyler et al., 2016; Wilcox et al., 2015).

We were able to explain, in a single analysis, over half of the variation in plastic exposure by using a signal regression model that incorporated differences in their home range across a wide range of species from several different taxonomic classes with different ecological backgrounds. With this approach we found that species with low motilities or smaller home ranges are more likely to encounter and be exposed to plastic closer to their core home range while species with greater (regional) motilities and larger home ranges have a greater area over which they might encounter debris, hence they may be more likely to do so. This suggests that, depending on local plastic concentrations and species motilities within their home range, 'risk hotspots' may be larger than one might expect. In addition to including species' home range, it was important to consider the probability of finding a species within a given location as it would provide a proxy for the abundance of the species, rather than only considering the presence/absence of the species. This is useful for quantifying exposure since the locations where species with plastic ingestion were reported may not necessarily be representative of their area; however, the overlap in diversity would compensate for this, allowing us to identify hotspot areas that otherwise might be missed. Moreover, including a weighted distance buffer for each study-species observation improved the specificity for predictions of location and species, thus allowing the model to consider the environment and debris fields directly adjacent to the distribution range and density of the study species, thereby estimating their risk of exposure to plastic pollution.

Life history traits of the studied species significantly improved the predictive power of the risk assessment model. In addition to species motilities and their probability of occurrence, taxonomic classification was an important factor in predicting plastic ingestion. Species from the classes Actinopterygii, Chondrichthyes, Mammalia, and Reptilia were found to be at high risk of ingesting plastic. For example, the loggerhead turtle (Caretta caretta) showed a mean predicted probability of plastic ingestion of 0.40 across the entire region, consistent with previous studies that have documented plastic ingestion by loggerheads (Camedda et al., 2014; Schuyler et al., 2016). No significant differences were found within the class Cephalopoda, which may be attributed to their active predation (as plastics could be transferred through their prey), high metabolism and relatively short life cycle (Llpiński, 1998). As observed elsewhere (Wilcox et al., 2015), body size was a leading factor for predicting ingestion where the gut volume was directly related to the amount of plastic remaining and accumulating in the stomach contents of species over time. Moreover, by including body size as a factor, we are implicitly include the size of plastic items into the model as previous studies have found that there is a relationship between the number of items a species can ingest; for example, larger species ingest more items and viceversa (Wilcox et al., 2018, 2015). Although studies have identified size, weight and volume of ingested plastic marine debris, there is still a great amount of uncertainty as to the residency time of plastic in the stomach contents or the potential sub-lethal impacts of ingesting plastic (Hoarau et al., 2014). Additionally, species' pelagic and demersal habitats also contributed to their risk of ingesting marine plastic, confirming results from a previous study (Reisser et al., 2014). Based on habitat type, demersal species were at a higher risk of ingesting marine plastic than pelagic species. This is in accordance with the high impact index for marine litter ingestion assigned to species living in the demersal compartment (48\%) compared to those in pelagic habitats (43\%) (Fossi et al., 2017). Overall, the results of this study are in agreement with similar risk assessments (Pennino et al., 2017; Schuyler et al., 2016; Wilcox et al., 2015). By combining percentage ingestion and life history traits, we sucessfully predicted ingestion across species' distribution ranges.

In the present work we provide a regional risk model across the Mediterranean Sea highlighting areas of concern by quantifying where 
high species diversity and high plastic densities overlap. A key finding throughout the region is that species in coastal areas are at a higher risk of ingesting plastic pollution, providing further evidence of the impacts of a single stressor in coastal areas. This is similar to findings from previous studies evaluating cumulative impacts on coastal biodiversity (Coll et al., 2010). For example, we identified areas of high plastic concentration where the overall risk of plastic ingestion was high, particularly along the Spanish western Mediterranean coast and the Alboran and Balearic Sea (Fig. 3B). These areas have large coastal populations and dense maritime traffic moving throughout the area and the Strait of Gibraltar, both of which have been identified as major contributors to marine plastic. Coastal areas are already known hotspot areas for cumulative anthropogenic impacts (Halpern, 2008; Halpern et al., 2007) affecting global marine ecosystems. In other areas in the Mediterranean Sea, high risk of ingestion was identified in the Pelagos Sanctuary in the NW Mediterranean, which is an important feeding and breeding area for Physeter macrocephalus (Fig. 3C) (Camedda et al., 2014; Fossi et al., 2017), and in the Aegean Sea (Fig. 3D). Both areas have been found to be hotspot regions for plastic ingestion as well as spatial overlap where high concentrations of plastic pollution are present. A recent study in the Adriatic found that plastic particles stay afloat for an average of 47 days, moving with the currents and remaining within local accumulating zones or gyres (Carlson et al., 2017). This is especially concerning as it shows that plastic can be transported long distances in a short time and species within Marine Protected Areas are at risk of ingesting plastic despite minimal direct contact with anthropogenic sources. These concerns have been reflected at the basin scale where species such as Caretta caretta, Thunnus thynnus and Physeter macrocephalus have been selected as bioindicator species for monitoring for macrolitter (Fossi et al., 2017). These species have a wide home range and results from this study have demonstrated that they are at a high risk of ingesting plastic pollution. In addition to protected areas, our results also allow us to make predictions for areas where there is currently a lack of data on the impacts of plastic debris such as the south-eastern Mediterranean coastline (Fig. 3E). Coincidently, these are also areas where coastal biodiversity in decreasing longitudinally considering current gaps in our knowledge on marine organisms along the southern and eastern coastal regions (Coll et al., 2010).

These results highlight the potential risk plastic has on the communities of local and regional species, especially in populated coastal areas where high loads of plastic can enter the marine environment, buttressing the need for management efforts in coastal areas to minimize human-driven impacts on coastal marine diversity (Jambeck et al., 2015; Liubartseva et al., 2018). Our results further indicate that marine diversity in coastal ecosystems is at high risk of ingesting marine plastic, regardless of the species. This is in agreement with studies identifying hotspot areas for the biodiversity of special conservation concern, especially for the Western Mediterranean Sea (Coll et al., 2010). Furthermore, fish species represented the majority of species with relatively high exposure rates. We acknowledge that improvements could be made, such as increasing sampling efforts in some under-studied parts of the Mediterranean Sea, the inclusion of ingestion in dietary studies, and the standardization of sampling methodologies would also help with interpretation across studies, taxa, and regions. Although we were able to substantially improve the modelling risk by including species' home range, other life history traits such as feeding strategy would further improve the identification of the risk of ingestion. In addition, the incorporation of a temporal component, which may be particularly useful for analysing seasonal trends and patterns of plastic ingestion.

Despite the predictive power of the analysis, there is still a great deal of uncertainty in estimating plastic exposure, especially prior to incorporating life history traits. Our model only explained $14 \%$ of the variation. The uncertainty attributed to plastic exposure can come from several sources, in particular, from sampling bias in ingestion studies. Compared to commercially important species where samples are more easily acquired, the uncertainty is higher, for key species that have smaller or declining populations where sampling for ingestion is difficult and is often performed during necropsies when a death occurs. In addition, there is also a certain amount of bias reporting among species and ingestion locations, where several areas within the Mediterranean Sea have little or no report or evidence of plastic ingestion. Another area of uncertainty concerns the amount of marine debris entering the marine environment at any given time, what happens to it and how much ends up in the stomachs of marine organisms (Gall and Thompson, 2015).

Spatial risk assessments are essential as management decisions are often contextualized and consider several factors to determine cumulative impacts. Although in this context we only consider one type of risk, plastic exposure, we also consider the risk for multiple species occupying a specific area. Using a risk framework to determine the risk of marine diversity to plastic pollution is valuable for understanding the overall threat plastic pollution poses to marine fauna, especially since most biodiversity regulations focus on the population or species level without connecting to the organizational level (Hardesty and Wilcox, 2017). A previous study integrating a spatially explicit risk assessment for several marine mammals in the Pelagos Sanctuary successfully identified hotspot areas that overlapped with areas of intense marine traffic (Pennino et al., 2017). Consequently, the development of ecological assessment tools, similar to this assessment risk analysis, can have important implications for the conservation and management of vulnerable marine species, such as the Caretta caretta and Physeter macrocephalus, at the basin scale.

Ecological links bond species with different feeding strategies; thus evaluating plastic ingestion in species that overlap spatially and temporally provides data that is extremely useful for making management decisions that consider the several factors linked to cumulative impacts. Even though it has been seen that some human-derived stressors (nutrient pollution, organic and inorganic pollution, coastal human pollution, light pollution, commercial and artisanal fishing, sea surface temperature anomalies, UV radiation anomalies, ocean acidification, sea level rise, oil rigs, invasive species, shipping and pollution from commercial shipping and from ports) show signs of decreasing their individual impact on the oceans, cumulative impacts of these stressors area generally increasing in coastal areas where human uses of the ocean are greatest (Halpern et al., 2015). Many of these stressors are better understood than plastic pollution, and are key priorities for short-term conservation interventions (Avery-gomm et al., 2018). Likewise, evaluating the risk of plastic ingestion is extremely important at the basin level where there is a need for management decisions to be harmonized between coastal Mediterranean countries, providing a tool for policymakers and researchers in those areas to determine where resources may best be allocated.

\section{Conclusions}

Plastic pollution is widespread and impacts marine diversity across the Mediterranean Sea. Due to the alarming concentrations of plastic in the marine environment, new modelling approaches are needed to identify which species are at risk and where. The modelling approach adopted in this study allowed for the evaluation of complex ecological systems to map out plastic ingestion hotspot areas, thus providing an adaptive approach for identifying species and geographic regions of high concern. Furthermore, the conceptual framework used in this study can be expanded to other regions in the world and to other marine species. Overall, findings from this work provide the foundation for monitoring and mitigating the impacts of plastic pollution on marine ecosystems in the Mediterranean Sea which can be extrapolated to other regions for future risk frameworks.

\section{Acknowledgements}

M.C. is the recipient of a pre-doctoral FPI Fellowship from the Conselleria d'Innovació, Recerca i Turisme of the regional Government 
of the Balearic Islands co-financed by the European Social Fund as part of the FSE 2014-2020 operational program. In addition, this study was partially funded by Ajuts per dur a terme Accions Especials de Recerca i Desenvolupament 2015-2016 del Govern de les Illes Balears, Ref: 17/ 2015. The research leading to these results has received funding from "la Caixa" Banking Foundation. BDH and CW were supported by CSIRO's Oceans and Atmosphere Business Unit. In addition, this study was partially funded by the European Commission DG Environment project: "Support Mediterranean Member States towards coherent and Coordinated Implementation of the second phase of the MSFD MEDCIS" under grant no. 11.0661/2016/748067/SUB/ENV.C2. Finally, acknoweldgements to the INTERREG project: Plastic Busters MPAs: preserving biodiversity from plastics in Mediterranean Marine Protected Areas, co-financed by the European Regional Development Fund (grant agreement No 4MED17_3.2_M123_027).

\section{Author contributions statement}

S.D., C.A. and M.C. jointly conceived the study; all authors contributed to the design of the study. M.C. and C.A. compiled the data. M.C. and $C \cdot W$. analysed the data. M.C. led the writing of the manuscript, with assistance from co-authors C.W, B.D.H., E.v.S., L.L., C.A. and S.D. All authors approved the final manuscript.

\section{Additional information}

The authors declare no competing interests.

\section{Appendix A. Supplementary data}

Supplementary data to this article can be found online at https://doi. org/10.1016/j.scitotenv.2019.04.355.

\section{References}

Alomar, C., Deudero, S., 2017. Evidence of microplastic ingestion in the shark Galeus melastomus Rafinesque, 1810 in the continental shelf off the western Mediterranean Sea. Environ. Pollut. 223, 223-229. https://doi.org/10.1016/j.envpol.2017.01.015.

Avery-gomm, S., Borrelle, S.B., Provencher, J.F., 2018. Linking Marine Plastic Ingestion Research to Wildlife Conservation. Conservation Biological Diversity 1492-1495. https://doi.org/10.1016/j.scitotenv.2018.04.409.

Bianchi, C.N., Morri, C., 2000. Marine biodiversity of the Mediterranean Sea: situation, problems and prospects for future research. Mar. Pollut. Bull. 40, 367-376. https:// doi.org/10.1016/S0025-326X(00)00027-8.

Boucher, J., Friot, D., 2017. Primary Microplastics in the Oceans: A Global Evaluation of Sources. IUCN, Gland, Switzerland.

Burnham, K.P., Anderson, D.R., 2003. Model Selection and Multimodel Inference: A Practical Information-Theoretic Approach. Springer Science \& Business Media.

Camedda, A., Marra, S., Matiddi, M., Massaro, G., Coppa, S., Perilli, A., Ruiu, A., Briguglio, P., de Lucia, G.A., 2014. Interaction between loggerhead sea turtles (Caretta caretta) and marine litter in Sardinia (Western Mediterranean Sea). Mar. Environ. Res. 100, 25-32.

Carlson, D.F., Suaria, G., Aliani, S., Fredj, E., Fortibuoni, T., Griffa, A., Russo, A., Melli, V. 2017. Combining litter observations with a regional ocean model to identify sources and sinks of floating debris in a semi-enclosed basin: the Adriatic Sea. Front. Mar. Sci. 4,78 .

Coll, M., Piroddi, C., Steenbeek, J., Kaschner, K., Lasram, F.B.R., Aguzzi, J., Ballesteros, E., Bianchi, C.N., Corbera, J., Dailianis, T., Danovaro, R., Estrada, M., Froglia, C., Galil, B.S., Gasol, J.M., Gertwage, R., Gil, J., Guilhaumon, F., Kesner-Reyes, K., Kitsos, M.S., Koukouras, A., Lampadariou, N., Laxamana, E., de la Cuadra, C.M.L.F., Lotze, H.K., Martin, D., Mouillot, D., Oro, D., Raicevich, S., Rius-Barile, J., Saiz-Salinas, J.I., Vicente, C.S., Somot, S., Templado, J., Turon, X., Vafidis, D., Villanueva, R., Voultsiadou, E., 2010. The biodiversity of the Mediterranean Sea: estimates, patterns, and threats. PLoS One 5. https://doi.org/10.1371/journal.pone.0011842.

Dawson, T.P., Jackson, S.T., House, J.I., Prentice, I.C., Mace, G.M., 2011. Beyond predictions: biodiversity conservation in a changing climate. Science 332, 53-58.

de Stephanis, R., Giménez, J., Carpinelli, E., Gutierrez-Exposito, C., Cañadas, A., 2013. As main meal for sperm whales: plastics debris. Mar. Pollut. Bull. 69, 206-214.

Derraik, J.G.B., 2002. The pollution of the marine environment by plastic debris: a review. Mar. Pollut. Bull. 44, 842-852.

Deudero, S., Alomar, C., 2015. Mediterranean marine biodiversity under threat: reviewing influence of marine litter on species. Mar. Pollut. Bull. 98, 58-68. https://oi.org/ 10.1016/j.marpolbul.2015.07.012.

Fossi, M.C., Pedà, C., Compa, M., Tsangaris, C., Alomar, C., Claro, F., Ioakeimidis, C., Galgani, F., Hema, T., Deudero, S., Romeo, T., Battaglia, P., Andaloro, F., Caliani, I., Casini, S.,
Panti, C., Baini, M., 2017. Bioindicators for monitoring marine litter ingestion and its impacts on Mediterranean biodiversity. Environ. Pollut. https://doi.org/10.1016/j. envpol.2017.11.019.

Gall, S.C., Thompson, R.C., 2015. The impact of debris on marine life. Mar. Pollut. Bull. 92, 170-179. https://doi.org/10.1016/j.marpolbul.2014.12.041.

Halpern, B., 2008. Managing for Cumulative Impacts in Ecosystem-Based Management through Ocean Zoning. https://doi.org/10.1016/j.ocecoaman.2007.08.002.

Halpern, B.S., Selkoe, K.A., Micheli, F., Kappel, C.V., 2007. Evaluating and Ranking the Vulnerability of Global Marine Ecosystems to Anthropogenic Threats 1-15. https://doi. org/10.1111/j.1523-1739.2007.00752.x.

Halpern, B.S., Frazier, M., Potapenko, J., Casey, K.S., Koenig, K., Longo, C., Lowndes, J.S. Rockwood, R.C., Selig, E.R., Selkoe, K.A., Walbridge, S., 2015. Spatial and temporal changes in cumulative human impacts on the world's ocean. Nat. Commun. 6, 1-7. https://doi.org/10.1038/ncomms8615.

Hardesty, B.D., Wilcox, C., 2017. A risk framework for tackling marine debris. Anal. Methods 9, 1429-1436. https://doi.org/10.1039/C6AY02934E.

Hoarau, L., Ainley, L., Jean, C., Ciccione, S., 2014. Ingestion and defecation of marine debris by loggerhead sea turtles, Caretta caretta, from by-catches in the South-West Indian Ocean. Mar. Pollut. Bull. 84, 90-96. https://doi.org/10.1016/j.marpolbul.2014.05.031.

Jambeck, J.R., Geyer, R., Wilcox, C., Siegler, T.R., Perryman, M., Andrady, A., Narayan, R., Law, K.L., 2015. Plastic Waste Inputs from Land into the Ocean.

Jeftic, L., Sheavly, S., Adler, E., et al., 2009. Marine Litter: A Global Challenge. UNEP.

Kaschner, K., Rius-Barile, J., Kesner-Reyes, K., Garilao, C., Kullander, S., Rees, T., Froese, R., 2013. AquaMaps. Predicted range maps for aquatic species World Wide Web electronic publication, Version 8, 2013.

Leathwick, J.R., Elith, J., Hastie, T., 2006. Comparative performance of generalized additive models and multivariate adaptive regression splines for statistical modelling of species distributions. Ecol. Model. 199, 188-196.

Lebreton, L.-M., Greer, S.D., Borrero, J.C., 2012. Numerical modelling of floating debris in the world's oceans. Mar. Pollut. Bull. 64, 653-661.

Liubartseva, S., Coppini, G., Lecci, R., Clementi, E., 2018. Tracking plastics in the Mediterranean: 2D Lagrangian model. Mar. Pollut. Bull. 129, 151-162. https://doi.org/10.1016/ j.marpolbul.2018.02.019.

Llpiński, M.R., 1998. Cephalopod life cycles: patterns and exceptions. S. Afr. J. Mar. Sci. 20, 439-447. https://doi.org/10.2989/025776198784126205.

Löhr, A., Savelli, H., Beunen, R., Kalz, M., Ragas, A., Van Belleghem, F., 2017. Solutions for global marine litter pollution. Curr. Opin. Environ. Sustain. 28, 90-99. https://doi. org/10.1016/j.cosust.2017.08.009.

Lusher, A.L., Mchugh, M., Thompson, R.C., 2013. Occurrence of microplastics in the gastrointestinal tract of pelagic and demersal fish from the English Channel. Mar. Pollut. Bull. 67, 94-99. https://doi.org/10.1016/j.marpolbul.2012.11.028.

Maximenko, N., Hafner, J., Niiler, P., 2012. Pathways of marine debris derived from trajectories of Lagrangian drifters. Mar. Pollut. Bull. 65, 51-62.

Neufeld, L., Stassen, F., Sheppard, R., Gilman, T., 2016. The new plastics economy: Rethinking the future of plastics. World Economic Forum.

Otero, M.D.M., Conigliaro, M., 2012. Marine Mammals and Sea Turtles of the Mediterranean and Black Seas.

Pennino, M.G., Arcangeli, A., Prado Fonseca, V., Campana, I., Pierce, G.J., Rotta, A., Bellido J.M., 2017. A spatially explicit risk assessment approach: cetaceans and marine traffic in the Pelagos Sanctuary (Mediterranean Sea). PLoS One 12, 1-15. https://doi.org/ 10.1371/journal.pone.0179686.

Reisser, J., Shaw, J., Hallegraeff, G., Proietti, M., Barnes, D.K. a, Thums, M., Wilcox, C. Hardesty, B.D., Pattiaratchi, C., 2014. Millimeter-sized marine plastics: a new pelagic habitat for microorganisms and invertebrates. PLoS One https://doi.org/10.1371/journal.pone.0100289.

Rodríguez, B., Bécares, J., Rodríguez, A., Arcos, J.M., 2013. Incidence of entanglements with marine debris by northern gannets (Morus bassanus) in the non-breeding grounds. Mar. Pollut. Bull. 75, 259-263. https://doi.org/10.1016/j.marpolbul.2013.07.003.

Schuyler, Q.A., Wilcox, C., Townsend, K.A., Wedemeyer-Strombel, K.R., Balazs, G., Sebille E., Hardesty, B.D., 2016. Risk analysis reveals global hotspots for marine debris ingestion by sea turtles. Glob. Chang. Biol. 22, 567-576.

Seitz, R.D., Wennhage, H., Bergström, U., Lipcius, R.N., Ysebaert, T., 2013. Ecological value of coastal habitats for commercially and ecologically important species. ICES J. Mar. Sci. 71, 648-665

Suaria, G., Avio, C.G., Mineo, A., Lattin, G.L., Magaldi, M.G., Belmonte, G., Moore, C.J., Regoli, F., Aliani, S., 2016. The Mediterranean Plastic Soup: Synthetic Polymers in Mediterranean Surface Waters. Nature Publishing Group, pp. 1-10 https://doi.org/10.1038/ srep37551.

Taylor, M.L., Gwinnett, C., Robinson, L.F., Woodall, L.C., 2016. Plastic Microfibre Ingestion by Deep-Sea Organisms. Nature Publishing Group, pp. 1-9 https://doi.org/10.1038/ srep33997.

R Core Team, 2017. R: A language and environment for statistical computing. R Foundation for Statistical Computing, Vienna, Austria https://www.R-project.org/.

van Sebille, E., Wilcox, C., Lebreton, L., Maximenko, N., Hardesty, B.D., van Franeker, J.A., Eriksen, M., Siegel, D., Galgani, F., Law, K.L., 2015. A global inventory of small floating plastic debris. Environ. Res. Lett. 10, 124006. https://doi.org/10.1088/1748-9326/10/ 12/124006.

Wilcox, C. Sebille, E. Van, Denise, B., 2015. Threat of Plastic Pollution to Seabirds Is Global, Pervasive, and Increasing. , p. 112 https://doi.org/10.1073/pnas.1502108112.

Wilcox, C., Puckridge, M., Schuyler, Q.A., Townsend, K., Hardesty, B.D., 2018. A quantitative analysis linking sea turtle mortality and plastic debris ingestion. Sci. Rep. 8, 1-11. https://doi.org/10.1038/s41598-018-30038-z.

Wood, S., 2007. The Mgcv Package. www.r-project.org. 